\title{
ABO blood group and ovarian reserve: a meta-analysis and systematic review
}

\author{
Jie Deng ${ }^{1}$, Mengmeng Jia ${ }^{1}$, Xiaolin Cheng ${ }^{1}$, Zhen Yan ${ }^{1}$, Dongmei Fan ${ }^{1}$ and Xiaoyu \\ Tian $^{1}$ \\ ${ }^{1}$ Department of Obstetrics and Gynecology, The First Affiliated Hospital, and College of Clinical Medicine of Henan University \\ of Science and Technology, Luoyang, China
}

Correspondence to: Xiaoyu Tian, email: xyt161123@163.com

Keywords: $A B O$ blood group, ovarian reserve, systematic review, meta-analysis

Received: November 30, $2016 \quad$ Accepted: February 10, $2017 \quad$ Published: February 27, 2017

Copyright: Deng et al. This is an open-access article distributed under the terms of the Creative Commons Attribution License (CC-BY), which permits unrestricted use, distribution, and reproduction in any medium, provided the original author and source are credited.

\section{ABSTRACT}

Ovarian reserve reflects a woman's fertility potential. The ABO blood group system is a very stable genetic marker. Although many recent studies have explored the relationship between ABO blood group and ovarian reserve, a consensus has not yet been reached. This paper is the first meta-analysis and systematic review of the relationship between $A B O$ blood type and ovarian reserve. We analyzed seven cross-sectional studies evaluating follicle stimulating hormone (FSH) or anti-Mullerian hormone (AMH) levels in 55,113 participants to determine ovarian reserve. This study found no relationship between ABO blood type and ovarian reserve when FSH was used as an indicator of ovarian reserve (A vs non-A:OR=1.03, 95\% CI:0.96-1.11; B vs non-B: $O R=0.98$, 95\% CI:0.75-1.29; $A B$ vs non-AB:OR=0.96, 95\% CI:0.71-1.30; $O$ vs non-0:OR=1.03, 95\%CI:0.74-1.43). There was also no relationship between $A B O$ blood type and ovarian reserve when $A M H$ was used as an indicator (A vs non-A:OR=0.89, 95\% CI:0.76-1.03; B vs non-B:OR=1.02, 95\% CI:0.80-1.30; $A B$ vs non-AB:OR=1.14, 95\% CI:0.80-1.64, O vs non-O:OR=1.07, 95\% CI:0.86-1.34). Overall, the current study found no relationship between $A B O$ blood group and ovarian reserve. However, additional rigorous, high-quality and multi-indicator studies with large sample sizes are required for further verification.

\section{INTRODUCTION}

Ovarian reserve refers to reproductive potential as a function of the number and quality of remaining oocytes [1]. Recently, changes in the social environment, lifestyle and prolonged female reproductive years have led to gradual increases in female infertility $[2,3]$. Statistically, approximately $10 \%$ of infertile women have decreased ovarian reserve (DOR) [4], causing altered hormone levels that largely clinically manifest as peri-menopausal symptoms, such as hot flashes, sweating, anxiety, irritability, insomnia and other symptoms [5]. DOR also gradually evolves into premature ovarian failure (POF), which contributes to osteoporosis, cardiovascular disease and other related health issues [6].These conditions have serious impacts on a woman's reproductive health and quality of life and also place a certain burden on the family and society.
In evaluating ovarian reserve, recent studies have focused on age, antral follicle count(AFC), and hormones, particularly follicle stimulating hormone(FSH) and antiMullerian hormone(AMH), all of which can serve as indicators of ovarian reserve [7]. The basal FSH value, defined as the serum level during the first 2-3 days of the menstrual cycle, can be used for screening, counseling and other diagnostic purposes. The method used for detection is simple, economical, highly reproducible, and widely applied in clinical practice [8].The sensitivity and specificity of AMH in predicting ovarian response are high [9], and this hormone shows no significant fluctuations during the menstrual cycle [10]. AMH measurement is also convenient and rapid, with great potential in clinical application.

ABO blood group antigens are the glycoproteins or glycolipids that are distributed on the red blood cell membrane. These molecules are expressed not only on the 
surface of red blood cells but also on a variety of human cells and tissues, including epithelial cells, platelets, the vascular endothelium and neurons $[11,12]$. Studies have shown that ABO blood group is related to the occurrence of cardiovascular disease, cancer and other diseases $[13,14]$.In initial studies of the pathogenesis of ovarian hyperstimulation syndrome (OHSS), it was found that von Willebrand factor (VWF) levels might correlate with the development of OHSS [15]. Donnell [16] found that OHSS occurs when compared with patients with blood type A, blood type $\mathrm{O}$ in patients with VWF and VIII factor concentration will decrease. In addition, Binder et al [17] found that patients with blood type O develop OHSS less frequently, while blood type A is more likely to be associated with early-onset OHSS. Such findings promoted interest in the relationship between $\mathrm{ABO}$ blood type and DOR. Although recent studies have explored the relationship between blood type and ovarian reserve, the results are contradictory. In 2011, Nejat et al [18] suggested that blood type $\mathrm{O}$ was a risk factor for DOR, whereas presence of the A antigen (blood types A or AB) was protective for ovarian reserve. In 2013, Timberlake et al [19] failed to find a link between blood type and reduced ovarian reserve. Furthermore, Lin et al [20] suggested that the incidence of DOR was low in Chinese women with blood type $\mathrm{O}$ and that presence of the $\mathrm{B}$ antigen (blood types $\mathrm{B}$ or $\mathrm{AB}$ ) was a risk factor for $\mathrm{DOR}$. Thus, controversy remains with regard to whether blood type is related to ovarian reserve and which antigen is protective or a risk factor.

To elucidate the relationship between ABO blood type and ovarian reserve, we used literature to date to conduct a meta-analysis and systematic review.

\section{RESULTS}

\section{Screening results}

As shown in Figure 1, 692 articles were initially identified using a comprehensive search, of which 438 remained after duplicate results were removed. Among these studies, 420 were deemed irrelevant after reading the abstracts and/or did not meet the inclusion criteria; thus, they were excluded. A total of 18 potentially eligible articles were reviewed by analyzing the full text. Based

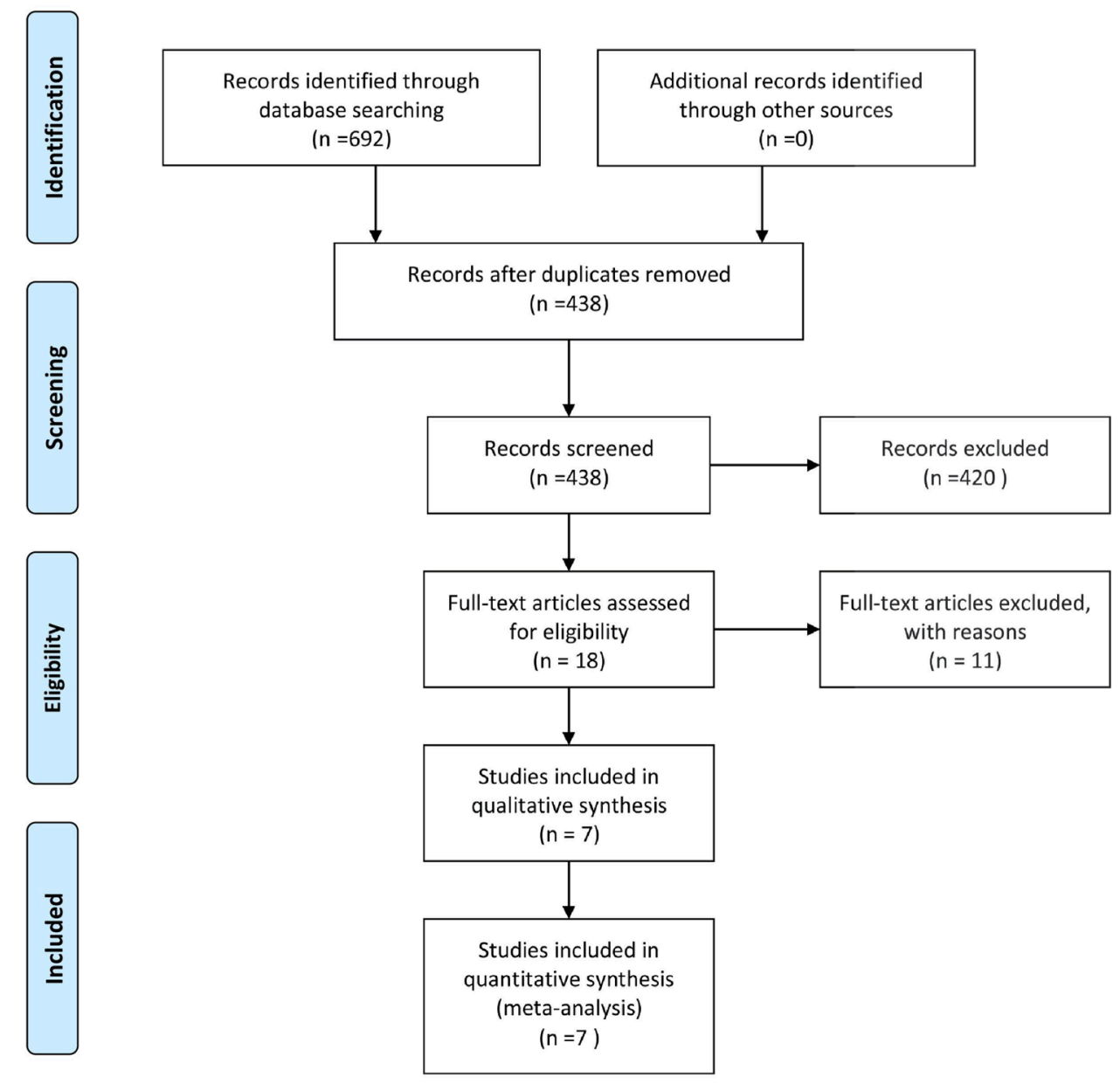

Figure 1: Flow-chart of study selection. 
Table 1: Characteristics of the included studies

\begin{tabular}{|c|c|c|c|c|c|c|}
\hline & $\begin{array}{|cc|}\begin{array}{l}\text { Determination } \\
\text { of }\end{array} & \text { ovarian } \\
& \text { reserve } \\
\end{array}$ & Age(year) & Race & case & control & Main result \\
\hline $\begin{array}{l}\text { Nejat } \\
{[18]}\end{array}$ & FSH & $\begin{array}{l}<45 \\
\text { (median age } 35, \\
\text { inter-quartile } \\
\text { range } \\
30-39 \text { ) } \\
\end{array}$ & $\begin{array}{l}\text { American } \\
\text { (different } \\
\text { ethnicities) }\end{array}$ & \begin{tabular}{|l|}
65 \\
A $16(24.6 \%)$ \\
B $8(12.3 \%)$ \\
AB $1(1.5 \%)$ \\
O $40(61.5 \%)$ \\
\end{tabular} & \begin{tabular}{|l|}
479 \\
A $173(36.1 \%)$ \\
B $77(16.0 \%)$ \\
AB 24(5.0\%) \\
O 205(42.8\%) \\
\end{tabular} & $\begin{array}{l}\text { A antigen (blood types } \\
\text { A or } \mathrm{AB} \text { ) was protective } \\
\text { for ovarian reserve, } \\
\text { blood type } \mathrm{O} \text { was a risk } \\
\text { factor for DOR. }\end{array}$ \\
\hline $\begin{array}{l}\text { Timberlake } \\
2013 \text { [19] }\end{array}$ & FSH & $\begin{array}{l}\text { Average age } \\
\text { 36.5(Range27-46) }\end{array}$ & $\begin{array}{l}\text { American } \\
\text { (different } \\
\text { ethnicities) }\end{array}$ & $\begin{array}{l}151 \\
\text { A 68(45.0\%) } \\
\text { O 64(42.4\%) }\end{array}$ & $\begin{array}{l}154 \\
\text { A } 62(40.2 \%) \\
\text { O } 71(46.1 \%)\end{array}$ & $\begin{array}{l}\text { Found no relationship } \\
\text { between ABO blood } \\
\text { group and ovarian } \\
\text { reserve. }\end{array}$ \\
\hline Lin 2014 [20] & FSH & $\begin{array}{l}<45 \\
\text { average age } \\
32.47 \pm 4.58\end{array}$ & China & $\begin{array}{l}3356 \\
\text { A } 955(28.5 \%) \\
\text { B } \\
1212(36.1 \%) \\
\text { AB } \\
395(11.8 \%) \\
\text { O } 794(23.6 \%)\end{array}$ & \begin{tabular}{|l|}
32123 \\
$\mathrm{~A}$ \\
$8906(27.7 \%)$ \\
$\mathrm{B}$ \\
$10183(31.7 \%)$ \\
$\mathrm{AB}$ \\
$3245(10.0 \%)$ \\
$\mathrm{O}$ \\
$9789(30.5 \%)$ \\
\end{tabular} & $\begin{array}{l}\text { Blood type } \mathrm{O} \text { was } \\
\text { protective for ovarian } \\
\text { reserve; B antigen } \\
\text { (blood types B or AB) } \\
\text { was a risk factor for } \\
\text { DOR. }\end{array}$ \\
\hline $\begin{array}{l}\text { Sengul } \\
2014[21]\end{array}$ & FSH & $\begin{array}{l}\text { Range } \\
18-45\end{array}$ & Turkey & $\begin{array}{l}62 \\
\text { A } 28(45.1 \%) \\
\text { B } 8(12.9 \%) \\
\text { AB } 4(6.5 \%) \\
\text { O } 22(35.5 \%) \\
\end{array}$ & \begin{tabular}{|l|}
438 \\
A $171(39.0 \%)$ \\
B 69(15.8\%) \\
AB 43(9.8\%) \\
O $155(35.4 \%)$ \\
\end{tabular} & $\begin{array}{l}\text { Found no relationship } \\
\text { between ABO blood } \\
\text { group and ovarian } \\
\text { reserve. }\end{array}$ \\
\hline $\mathrm{Mu} 2016[22]$ & FSH & $\begin{array}{l}\text { average age } \\
31.1 \pm 4.37\end{array}$ & China & $\begin{array}{l}2589 \\
\text { A } 814(31.4 \%) \\
\text { B } 590(22.8 \%) \\
\text { AB } 175(6.8 \%) \\
\text { O } \\
1010(39.0 \%)\end{array}$ & \begin{tabular}{|l|}
12286 \\
$\mathrm{~A}$ \\
$3794(30.9 \%)$ \\
$\mathrm{B}$ \\
$3061(24.9 \%)$ \\
$\mathrm{AB} 951(7.7 \%)$ \\
$\mathrm{O}$ \\
$4480(36.5 \%)$ \\
\end{tabular} & $\begin{array}{l}\text { B antigen (blood types } \\
\mathrm{B} \text { or } \mathrm{AB} \text { )was protective } \\
\text { for ovarian reserve; } \\
\text { blood type } \mathrm{O} \text { was a risk } \\
\text { factor for DOR. }\end{array}$ \\
\hline $\begin{array}{l}\text { Mouzon } \\
2012[23]\end{array}$ & $\mathrm{AMH}$ & $\begin{array}{l}\text { average age } \\
35.6 \pm 5.1\end{array}$ & France & $\begin{array}{l}277 \\
\text { A } 113(40.8 \%) \\
\text { B } 40(14.4 \%) \\
\text { AB } 11(3.9 \%) \\
\text { O } 113(40.8 \%) \\
\end{array}$ & \begin{tabular}{|l|}
739 \\
A 311(42.0\%) \\
B 89(12.0\%) \\
AB 25(3.4\%) \\
O 314(42.5\%) \\
\end{tabular} & $\begin{array}{l}\text { Found no relationship } \\
\text { between ABO blood } \\
\text { group and ovarian } \\
\text { reserve. }\end{array}$ \\
\hline $\begin{array}{l}\text { Pereira } \\
2013[24]\end{array}$ & AMH & 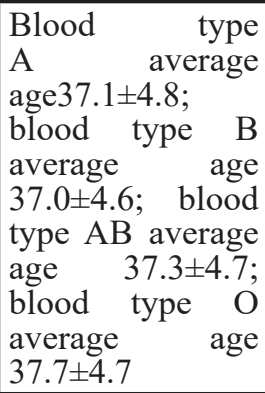 & American & $\begin{array}{l}1700 \\
\text { A } 611(35.9 \%) \\
\text { B 303(17.8\%) } \\
\text { AB } 88(5.1 \%) \\
\text { O } 698(41.0 \%)\end{array}$ & $\begin{array}{l}694 \\
\text { A } 274(39.5 \%) \\
\text { B } 130(18.7 \%) \\
\text { AB 32(4.6\%) } \\
\text { O 258(37.2\%) }\end{array}$ & $\begin{array}{l}\text { Found no relationship } \\
\text { between ABO blood } \\
\text { group and ovarian } \\
\text { reserve. }\end{array}$ \\
\hline
\end{tabular}

FSH: follicle stimulating hormone

AMH: anti-Mullerian hormone

DOR: decreased ovarian reserve

on this analysis, seven published studies [18-24] were included in this meta-analysis.

\section{Study characteristics}

The selected studies were conducted in four countries and published between 2011 and 2016. A total of 55,113 participants were included, with 8200 in the decreased ovarian reserve group and 46,913 in the control group. The studies were divided into two aspects according to the method used to determine ovarian reserve: five used FSH, and two used AMH. The major characteristics of the included studies are shown in Table 1. 
Table 2: Newcastle-Ottawa Scale table.

\begin{tabular}{|c|c|c|c|c|}
\hline & $\begin{array}{l}\text { the selection of the study } \\
\text { groups }\end{array}$ & $\begin{array}{l}\text { he comparability of the } \\
\text { groups }\end{array}$ & $\begin{array}{l}\text { the ascertainment of exposure } \\
\text { or outcome of interest }\end{array}$ & Total \\
\hline Nejat 2011 & 3 & 1 & \begin{tabular}{|c|}
3 \\
\end{tabular} & 7 \\
\hline Timberlake 2013 & 3 & 2 & 3 & 8 \\
\hline Lin 2014 & 3 & 2 & 3 & 8 \\
\hline Sengul 2014 & 3 & 2 & 3 & 8 \\
\hline Mu 2016 & 3 & 2 & 3 & 8 \\
\hline Mouzon 2012 & 3 & 0 & 3 & 6 \\
\hline Pereira 2013 & 3 & 0 & 3 & 6 \\
\hline
\end{tabular}

\section{Quality assessment}

The results of the quality assessment are shown in Table 2, with the scores ranging from 6 to 8 . All of the studies were identified as having relatively high quality.

\section{Outcomes}

The five studies that used FSH to detect ovarian reserve were analyzed to determine the odds ratio (OR) value of decreased ovarian reserve in the $\mathrm{ABO}$ blood group. For blood type A, the effective value was1.03, and the $95 \%$ confidence interval (CI) was $0.96-1.11$ (Figure 2). This finding suggests no association between blood type A and ovarian reserve in this sample with low heterogeneity $\left(\mathrm{I}^{2}=17 \%\right)$. Although not all studies on blood type B and AB supply data have also found similar results $(\mathrm{OR}=$ 0.98, 95\% CI:0.75-1.29; OR =0.96, 95\% CI:0.71-1.30, respectively) (Figures 3 and 4), there was no association between blood type $\mathrm{B}$ or blood type $\mathrm{AB}$ and ovarian reserve in these samples with high heterogeneity $\left(\mathrm{I}^{2}=88 \%\right.$ and $\mathrm{I}^{2}=75 \%$, respectively) (Figure 5). Similarly, there was no association between blood type $\mathrm{O}$ and ovarian reserve $(\mathrm{OR}=1.03,95 \% \mathrm{CI}$ : 0.74-1.43), and this sample also exhibited high heterogeneity $\left(\mathrm{I}^{2}=94 \%\right)$. These data indicate that there is no relationship between $\mathrm{ABO}$ blood type and ovarian reserve when FSH is used as the indicator of ovarian reserve.

The two studies that employed AMH to detect ovarian reserve were also analyzed. For blood type A, the OR was 0.89 , and the $95 \%$ CI was $0.76-1.03$ (Figure 2 ), suggesting no association between blood type A and ovarian reserve in this sample with low heterogeneity $\left(\mathrm{I}^{2}\right.$ $=0 \%)$. Similarly, no association was found between blood type $\mathrm{B}$ and ovarian reserve $(\mathrm{OR}=1.02,95 \% \mathrm{CI}$ : 0.80-1.30; Figure 3); this sample also exhibited low heterogeneity $\left(\mathrm{I}^{2}=24 \%\right)$. A similar result was found for blood type AB $(\mathrm{OR}=1.14,95 \% \mathrm{CI}: 0.80-1.64$; Figure 4$)$, suggesting no association between blood type $\mathrm{AB}$ and ovarian reserve, low heterogeneity was also observed in this sample $\left(\mathrm{I}^{2}=\right.$ $0 \%)$. The OR (1.07) and 95\% CI (0.86-1.34, Figure 5)

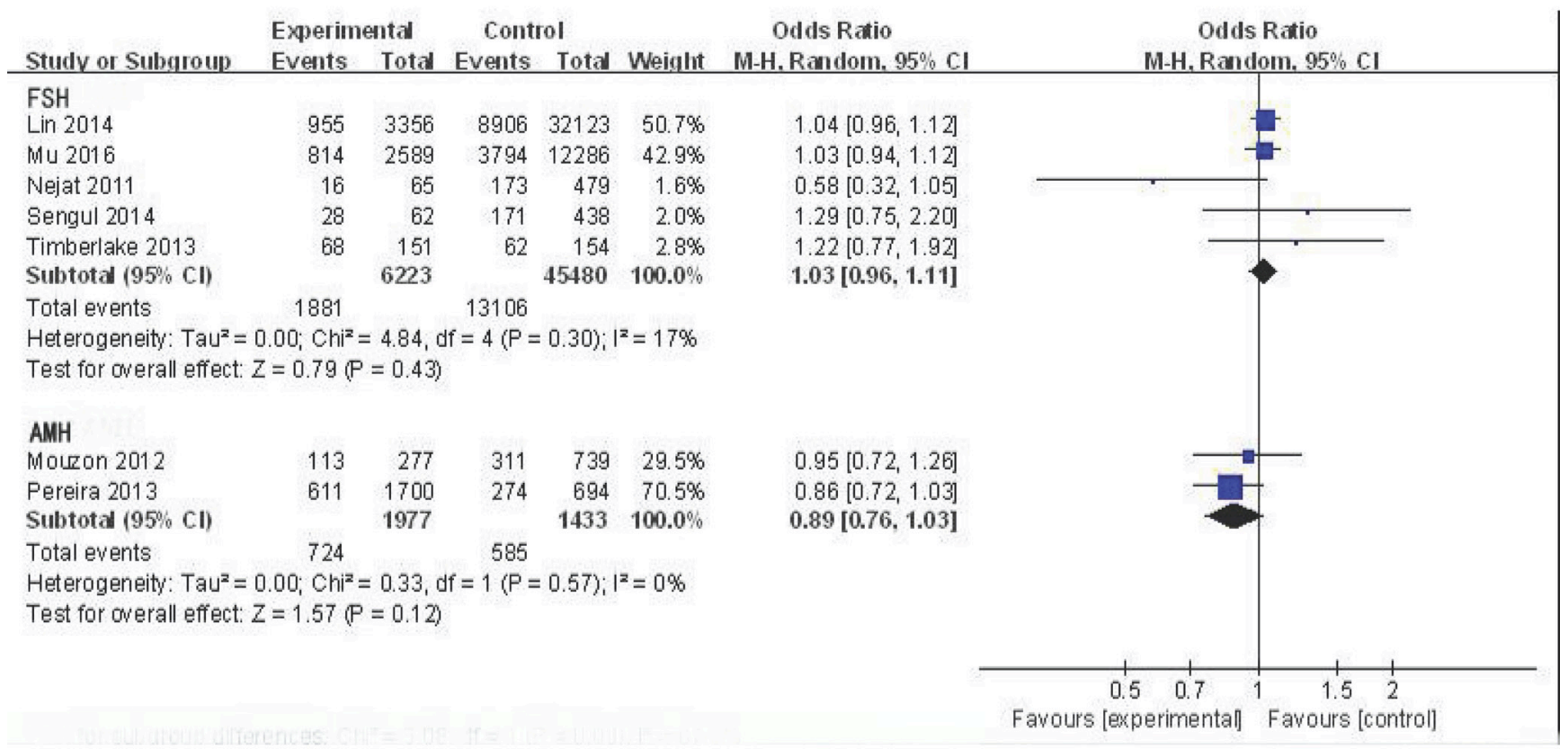

Figure 2: Forest plot of blood group A. 
for blood type $\mathrm{O}$ also suggested no association between blood type $\mathrm{O}$ and ovarian reserve in this sample with low heterogeneity $\left(\mathrm{I}^{2}=46 \%\right)$. The above data show that there is no relationship between $\mathrm{ABO}$ blood type and ovarian reserve when $\mathrm{AMH}$ is used as the indicator of ovarian reserve.

In conclusion, the current studies failed to find an association between $\mathrm{ABO}$ blood group and ovarian reserve.

\section{Sensitivity analyses}

Sensitivity analysis of the study with high heterogeneity (blood type $\mathrm{B}$, blood type $\mathrm{AB}$, blood type O study) found that after exclusion of the Lin et al [20] study, the heterogeneity for blood type B and blood type AB was reduced to $0\left(\mathrm{I}^{2}=0 \%\right)$, and that for blood type $\mathrm{O}$ also decreased significantly $\left(\mathrm{I}^{2}=58 \%\right)$. After exclusion of the Lin et al study, the effective OR for blood type B was 0.89 (95\% CI:0.8-0.98), changing the conclusion and indicating that blood type $\mathrm{B}$ is a protective factor for ovarian reserve. This sensitivity analysis showed that the results were not stable, and the high heterogeneity was derived from the Lin et al study. Detailed analysis of the Lin et al study with regard to the inclusion and exclusion criteria, research design, sample size, quality evaluation and other characteristics identified no differences in the inclusion and exclusion criteria, research design, quality evaluation or other characteristics relative to the other studies. In contrast, the sample size in the Lin et al study was twice as large as the sum of the other four studies, which influenced the outcome of the meta-analysis.

\section{DISCUSSION}

In recent years, several biological studies have indicated that blood type and ovarian reserve may be inextricably linked. The direct translation product of the ABO blood group gene is glycosyltransferase. FSH and luteinizing hormone $(\mathrm{LH})$ receptors are heavily glycosylated proteins, and $\mathrm{FSH}$ receptor expression in ovarian granulosa cells functions together with activated LH receptors to promote follicular development [25].Dharmesh and Baenziger [26] found that glycosyltransferases maintain the terminal glycosylation of LH with galactose-4-SO4 oligosaccharides, thereby affecting the cycle half-life of LH. Thus, it is reasonable to speculate that glycosyltransferases may be, to some extent, related to gamete production [27] and that a lack of these enzymes may lead to impaired gamete formation. In addition, studies have found that the NR5A1 gene is located at the core of the ABO gene and plays a role in transcriptional regulation in the hypothalamic-pituitaryovary (H-P-O) axis [28].Blocking the transcription and translation of the NR5A1 gene in mice causes different degrees of developmental defects in newborn gonads and adrenal glands, disturbed FSH and LH secretion by the adenohypophysis, and an abnormal hypothalamic median eminence structure [29]. A study of human ovarian tissue found that NR5A1 is expressed during almost every stage of a woman's life: the earliest expression was found in the fetus, with expression continuing to adulthood [30]. When NR5A1 expression is dysregulated, the follicles in the ovary cortex cannot mature normally, and the ovarian tissue cannot support normal ovulation.

There is no clear evidence from biological studies for a direct link between blood type and ovarian reserve,

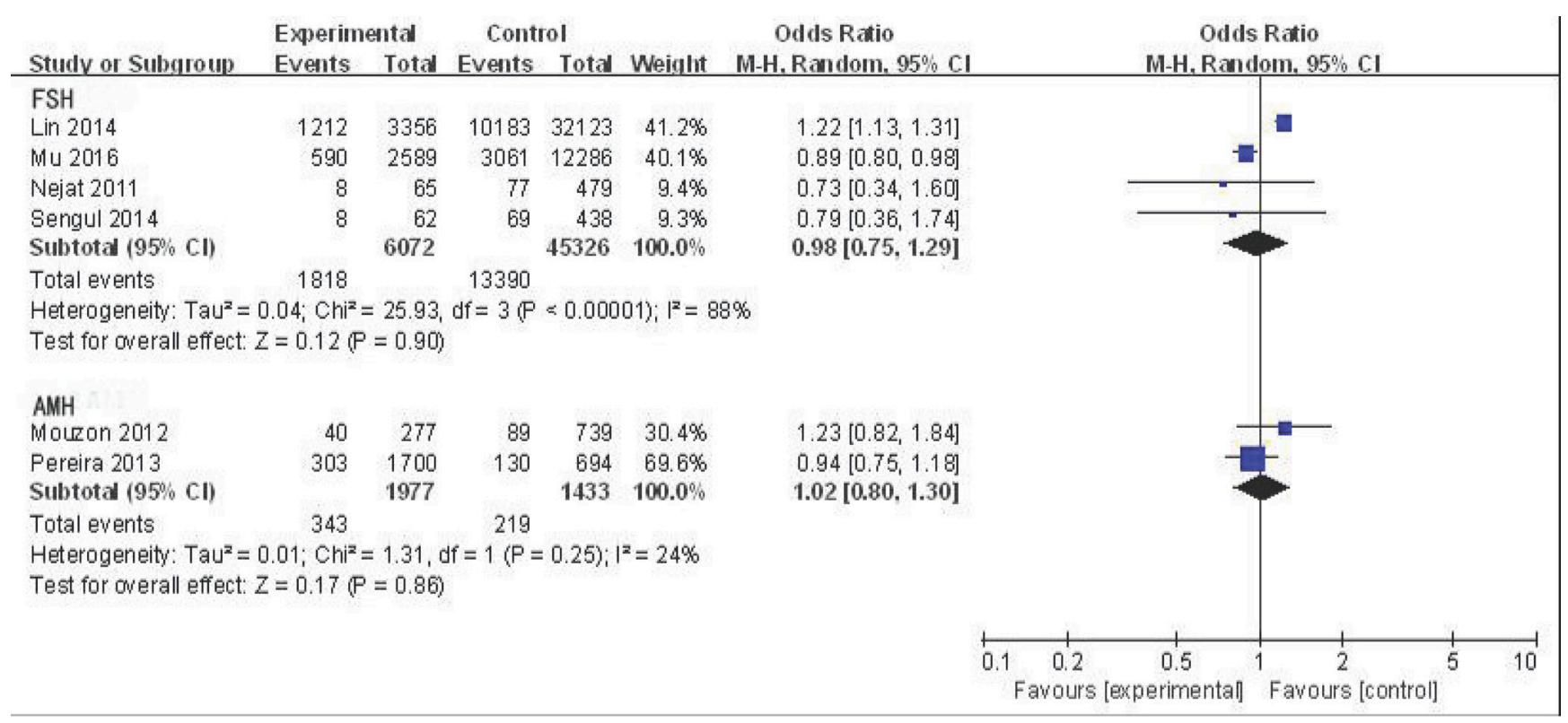

Figure 3: Forest plot of blood group B. 
and recent clinical studies have failed to reach a consensus regarding the relationship between the two, making systematic review particularly important. This paper reports the first meta-analysis and systematic evaluation of the relationship between ABO blood type and ovarian reserve. Our systematic review included seven studies that investigated FSH and $\mathrm{AMH}$, two indicators of ovarian reserve, with a total of 55,113 participants.

The current study failed to find an association between $\mathrm{ABO}$ blood group and ovarian reserve. This conclusion is not consistent with some clinical studies, and this discrepancy may exist because the Nejat et al [18] study did not establish a set time in the menstrual cycle at which to obtain serum samples (it should be noted that in the other four studies using FSH, the level was measured on the third day of the menstrual cycle). Although the study attempted to reduce the impact by analyzing E2 levels concomitantly with FSH, this may have potentially introduced bias. In addition, the authors used data from two centers to reduce race effects, but this may have increased other confounding factors. Accumulating evidence suggests that race and ethnicity influence the

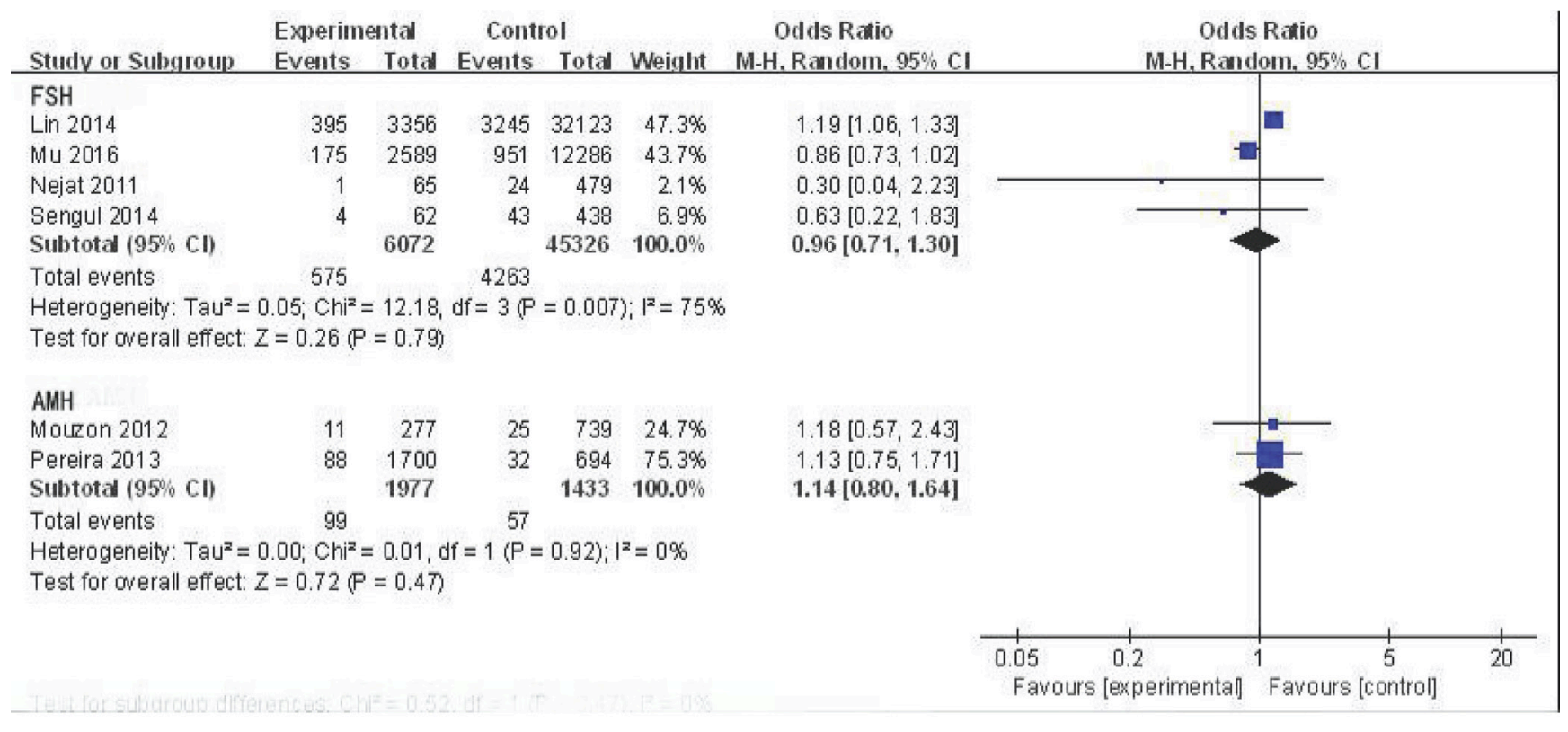

Figure 4: Forest plot of blood group AB.

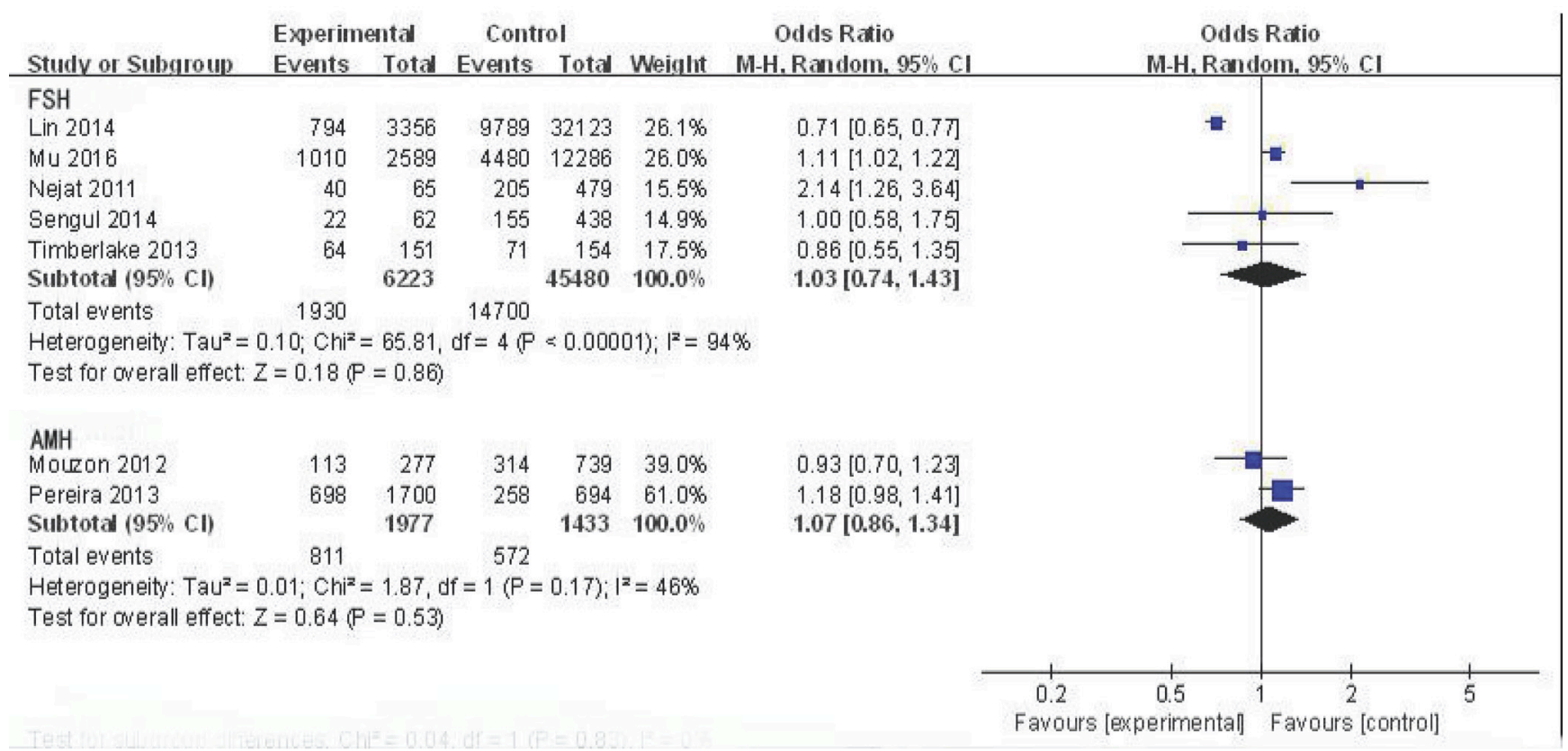

Figure 5: Forest plot of blood group $O$. 
frequency of different blood types. For example, the frequencies for the $\mathrm{O}, \mathrm{A}, \mathrm{B}$, and $\mathrm{AB}$ blood types are $44 \%$, $42 \%, 10 \%$, and $4 \%$, respectively, in the United States but are $29 \%, 27 \%, 32 \%$, and $13 \%$ [31], respectively, in China. In addition, there is evidence that ovarian reserve may also differ dramatically among races: compared with white women, Latina and Chinese women may have lower ovarian reserve and be at increased risk of early menopause [32]. The main confounding factors affecting ovarian function, such as smoking, previous chemotherapy or radiotherapy, ovarian surgery, and endometriosis [33], were not fully considered in the study design and may have also increased the risk of outcome bias.

Interestingly, a 2014 study by Spitzer et al. [34] did not use a direct serological method to determine ovarian reserve but rather utilized mature oocytes, fertilization rates and pregnancy rates to predict ovarian reserve. Their conclusion was similar to ours, finding no relationship between $\mathrm{ABO}$ blood group and ovarian reserve.

There are several limitations of this study. First, analysis of previous studies revealed that heterogeneity cannot be ignored. Although the selected articles did not differ with regard to inclusion and exclusion criteria, research design, quality assessment and other aspects, the large sample size of the Lin et al study made the results unreliable. Second, although AMH is a good prognostic marker of ovarian reserve, only a few recent studies have employed AMH as an indicator. Finally, our study included only infertile women, limiting the applicability of our findings to the general population.

In summary, the clinical evidence generated thus far has not identified a link between ABO blood type and ovarian reserve. However, the biological research hypotheses about the relationship between ABO blood type and ovarian reserve and the conclusion of this paper differ; therefore, it is necessary to confirm these results with additional far-reaching biological studies. Moreover, many different indices are currently used to measure ovarian reserve, and additional multi-indicator studies are needed in the future. In addition, considering the heterogeneity of our analysis and the limited number of studies, our results require further verification with additional rigorous, high-quality studies with large sample sizes.

\section{MATERIALS AND METHODS}

The protocol of this review was registered in PROSPERO under registration number CRD 42016046330 (http://www.crd.york.ac.uk/PROSPERO/).

\section{Inclusion and exclusion criteria}

The inclusion criteria were as follows, 1) The case group and control group needed to be from the same period and region; 2) FSH or AMH was evaluated to indicate ovarian reserve in the case and control groups (FSH $>10 \mathrm{IU} / \mathrm{L}$ or $\mathrm{AMH}<1.5 \mathrm{pg} / \mathrm{ml}$ was considered DOR [35]); 3) ABO blood group typing was clear, and the data were extractable; 4) Sufficient data were available to calculate the OR and $95 \% \mathrm{CI}$.

The following types of studies were excluded: nonoriginal studies; only abstracts without full-text data; repeated reports containing similar information or poor quality data that could not be used.

\section{Search strategy}

Electronic databases, including PubMed, the Science Citation Index (SCI), Cochrane Central, EMBASE, CINAHL, and Web of Science were searched. The search cut-off date was August 1, 2016.Both medical subject heading (MeSH) and text-word searches were employed using the following terms: "blood type" and "ovarian reserve". All the references included in this article were also searched to identify eligible studies. The language was restricted to English, but there were no country restrictions.

\section{Data collection}

Studies were independently selected by two reviewers based on the inclusion and exclusion criteria. Information regarding the literature, including the authors' names, institutions, or journals, was extracted by the reviewers during the selection process. Disagreements were resolved through discussion; if no consensus was reached, a third reviewer was consulted. If two or more reports included the same participants, then only the most recent report was included in the meta-analysis.

\section{Statistical analyses}

The main outcome was the incidence of DOR. Statistical analyses were performed using RevMan version 5.3, and ORs and 95\% CIs were used to measure outcomes. Q and Higgins $\mathrm{I}^{2}$ statistics were used to examine heterogeneity among studies. When $P \geq 0.1$ and $\mathrm{I}^{2} \leq 50 \%$, the included studies were considered to have little heterogeneity; when $P<0.1$ and $\mathrm{I}^{2}>50 \%$, the included studies were considered to have substantial heterogeneity [36].Because the random-effects model is relatively conservative, it was adopted to make the results more reliable [37]. Sensitivity analyses were performed to assess the impact of each study on the overall analysis to identify the source of heterogeneity. 


\section{Quality assessment}

The Newcastle-Ottawa Scale [38] was used to evaluate the research from three aspects: (1) the selection of the study groups; (2) the comparability of the groups; and (3) the ascertainment of exposure or outcome of interest. Each study could receive a score from 0 points (the lowest quality) to 9 points (the highest quality). Highquality studies were defined as those with a score of more than 6 points; otherwise, the studies were rated as poor quality.

\section{CONFLICTS OF INTEREST}

The authors have no conflicts of interest to declare.

\section{FINANCIAL SUPPORT}

None.

\section{REFERENCES}

1. Practice Committee of the American Society for Reproductive Medicine. Testing and interpreting measures of ovarian reserve: a committee opinion. Fertil Steril. 2015; 103: e9-e17.

2. Younglai EV, Holloway AC, Foster WG. Environmental and occupational factors affecting fertility and IVF success. Hum Reprod Update. 2005; 11: 43-57.

3. Wiener-Megnazi Z, Auslender R, Dirnfeld M. Advanced paternal age and reproductive outcome. Asian J Androl. 2012; 14: 69-76.

4. Maheshwari A, Fowler P, Bhattacharya S. Assessment of ovarian reserve--should we perform tests of ovarian reserve routinely? Hum Reprod. 2006; 21: 2729-2735.

5. de Zambotti M, Colrain IM, Baker FC. Interaction between reproductive hormones and physiological sleep in women. J Clin Endocrinol Metab. 2015; 100: 1426-1433.

6. Shuster LT, Rhodes DJ, Gostout BS, Grossardt BR, Rocca WA. Premature menopause or early menopause: long-term health consequences. Maturitas. 2010; 65: 161-166.

7. Knauff EA, Eijkemans MJ, Lambalk CB, ten Kate-Booij MJ, Hoek A, Beerendonk CC, Laven JS, Goverde AJ, Broekmans FJ, Themmen AP, de Jong FH, Fauser BC, Dutch Premature Ovarian Failure Consortium. AntiMullerian hormone, inhibin B, and antral follicle count in young women with ovarian failure. J Clin Endocrinol Metab. 2009; 94: 786-792.

8. Bancsi LF, Broekmans FJ, Mol BW, Habbema JD, te Velde ER. Performance of basal follicle-stimulating hormone in the prediction of poor ovarian response and failure to become pregnant after in vitro fertilization: a meta-analysis. Fertil Steril. 2003; 79: 1091-1100.

9. Broer SL, Dólleman M, Opmeer BC, Fauser BC, Mol BW,
Broekmans FJ. AMH and AFC as predictors of excessive response in controlled ovarian hyperstimulation: a metaanalysis. Hum Reprod Update. 2011; 17: 46-54.

10. Tsepelidis S, Devreker F, Demeestere I, Flahaut A, Gervy $\mathrm{Ch}$, Englert Y. Stableserum levels of anti-Müllerian hormone during the menstrual cycle: a prospective study in normo-ovulatory women. Hum Reprod. 2007; 22: 18371840.

11. Lowe JB. The blood group-specific human glycosyltransferases. Baillieres Clin Haematol. 1993; 6: 465-492.

12. Franchini M, Liumbruno GM. ABO blood group: old dogma, new perspectives. Clin Chem Lab Med. 2013; 51: 1545-1553.

13. Chen Z, Yang SH, Xu H, Li JJ. ABO blood group system and the coronary artery disease: an updated systematic review and meta-analysis. Sci Rep. 2016; 6: 23250.

14. Zhang BL, He N, Huang YB, Song FJ, Chen KX. ABO blood groups and risk of cancer: a systematic review and meta-analysis. Asian Pac J Cancer Prev. 2014; 15: 46434650.

15. Ogawa S, Minakami H, Araki S, Ohno T, Motoyama M, Shibahara H, Sato I. A rise of the serum level of Von Willebrand factor occurs before clinical manifestation of the severe form of ovarian hyperstimulation syndrome. J Assist Reprod Genet. 2001; 18: 114-119.

16. O'Donnell J, Laffan MA. The relationship between $\mathrm{ABO}$ histo-blood group, factorVIII and Von Willebrand factor. Transfus Med. 2001; 11: 343-351.

17. Binder H, Flegel WA, Emran J, Müller A, Dittrich R, Beckmann MW, Zingsem J,Eckstein R, Ringwald J. Association of blood group A with early-onset ovarianhyperstimulation syndrome. Transfus Clin Biol. 2008; 15: 395-401.

18. Nejat EJ, Jindal S, Berger D, Buyuk E, Lalioti M, Pal L. Implications of bloodtype for ovarian reserve. Hum Reprod. 2011; 26: 2513-2517.

19. Timberlake KS, Foley KL, Hurst BS, Matthews ML, Usadi RS, Marshburn PB. Association of blood type and patient characteristics with ovarian reserve. Fertil Steril. 2013; 100: 1735-1739.

20. Lin S, Li R, Chi H, Huang S, Zhang H, Zheng X, Liu P, Qiao J. Effect of ABO blood type on ovarian reserve in Chinese women. Fertil Steril. 2014; 102: 1729-32.e2.

21. Sengül O, Dilbaz B, Yerebasmaz N, Dede S, Altınbaş S, Erkaya S. Only female age, and not blood type, is associated with ovarian reserve. Int J Fertil Steril. 2014; 8: 143-146.

22. Mu L, Jin W, Yang H, Chen X, Pan J, Lin J, Wang P, Huang $\mathrm{X}$. ABO blood type is associated with ovarian reserve in Chinese women with subfertility. Oncotarget. 2016; 7: 50908-50913. doi: 10.18632/oncotarget.10766.

23. de Mouzon J, Hazout A, Cohen-Bacrie M, Belloc S, CohenBacrie P. Blood type and ovarian reserve. Hum Reprod. 2012; 27: 1544-5; author reply 1545-6. 
24. Pereira N, Levine BA, Karipcin FS, Elias RT, Spandorfer $\mathrm{SD}$, Rosenwaks Z. ABO blood type and variation in serum markers of ovarian reserve. Fertil Steril. 2013; 100: S155.

25. Replace with: Baird D. [Role of FSH and LH in follicle development]. [Article in French]. J Gynecol Obstet Biol Reprod (Paris). 2006; 35: 2S24-2S29.

26. Dharmesh SM, Baenziger JU. Estrogen modulates expression of the glycosyltransferases that synthesize sulfated oligosaccharides on lutropin. Proc Natl Acad Sci U S A. 1993; 90: 11127-11131.

27. Williams SA, Stanley P. Oocyte-specific deletion of complex and hybrid N-glycans leads to defects in preovulatory follicle and cumulus mass development. Reproduction. 2009; 137: 321-331.

28. Lin L, Achermann JC. Steroidogenic factor-1 (SF-1, Ad4BP, NR5A1) and disorders of testis development. Sex Dev. 2008; 2: 200-209.

29. Luo X, Ikeda Y, Parker KL. A cell-specific nuclear receptor is essential for adrenal and gonadal development and sexual differentiation. Cell. 1994; 77: 481-490.

30. Jeyasuria P, Ikeda Y, Jamin SP, Zhao L, De Rooij DG, Themmen AP. Cell-specific knockout of steroidogenic factor 1 reveals its essential roles in gonadal function. Mol Endocrinol. 2004; 18: 1610-1619.

31. Garratty G, Glynn SA, McEntire R, Retrovirus Epidemiology Donor Study. ABO and Rh(D) phenotype frequencies of different racial/ethnic groups in the United States. Transfusion. 2004; 44: 703-706.

32. Bleil ME, Gregorich SE, Adler NE, Sternfeld B, Rosen MP, Cedars MI. Race/ethnic disparities in reproductive age: an examination of ovarian reserve estimates across four race/ ethnic groups of healthy, regularly cycling women. Fertil Steril. 2014; 101: 199-207.
33. American College of Obstetricians and Gynecologists Committee on Gynecologic Practice and Practice Committee. Female age-related fertility decline. Committee Opinion No. 589. Fertil Steril. 2014; 101: 633-634.

34. Spitzer D, Corn C, Stadler J, Wirleitner B, Schuff M, Vanderzwalmen P, Grabher F, Zech NH. Implications of blood type for ovarian reserve and infertility - impact on oocyte yield in IVF patients. Geburtshilfe Frauenheilkd. 2014; 74: 928-932.

35. Caroppo E, Matteo M, Schonauer LM, Vizziello G, Pasquadibisceglie A, Vitti A, D'Amato G. Basal FSH concentration as a predictor of IVF outcome in older women undergoing stimulation with $\mathrm{GnRH}$ antagonist. Reprod Biomed Online. 2006; 13: 815-820.

36. Higgins JP, Green S. Cochrane handbook for systematic reviews of interventions, Vol. 5. (John Wiley \& Sons, Ltd: Chichester, UK), 2008.

37. Borenstein M, Hedges LV, Higgins JP, Rothstein HR. A basic introduction to fixed-effect and random-effects models for meta-analysis. Res Synth Methods. 2010; 1: 97 111.

38. Wells GA, Shea B, O'Connell D, Peterson J, Welch V, Losos M, Tugwell P. The Newcastle-Ottawa Scale (NOS) for assessing the quality if nonrandomized studies in meta-analyses. Ottawa Hospital: Research Institute, 2014. Available at: http://www.ohri.ca/programs/clinical_ epidemiology/oxford.htm. Accessed 2016 August 1. 